\title{
DETEKSI DINI GANGGUAN BELAJAR PADA ANAK DENGAN METODE FORWARD CHAINING DAN CERTAINTY FACTOR
}

\author{
Dhio Saputra ${ }^{1}$, Wifra Safitri ${ }^{2}$, Syafrika Deni Rizki ${ }^{3}$ \\ Sistem Informasi, Universitas Putra Indonesia YPTK Padang \\ Email :dhiosaputra@upiyptk.ac.id
}

\begin{abstract}
Abstrak: Gangguan belajar pada anak yang bermacam-macam yang mengakibatkan kesulitan dalam membaca, menulis, dan menghitung. Kebanyakan dari kalangan orang tua juga sering kali tidak mengenali jenis gangguan pada anak mereka yang seharusnya bisa diketahui dengan gejala - gejala yang dialami oleh anak. Sistem pakar ini dibangun untuk mendiagnosa jenis gangguan belajar pada anak usia 5 - 10 tahun. Dari sistem pakar ini dapat memberikan informasi mengenai jenis gangguan serta pencegahannya. Sistem pakar ini menggunakan metode inferensi Forward Chaining dan Certainty Factor. Hasil uji konsultasi dengan sistem ini menunjukkan bahwa sistem mampu menentukan jenis gangguan beserta solusi awal yang harus dilakukan, berdasarkan gejala-gejala yang sebelumnya dipilih oleh pengguna.
\end{abstract}

Kata Kunci: Sistem Pakar, Forward Chaining, Certainty Faktor, Gangguan Belajar

\begin{abstract}
Learning disorders in various children that cause difficulties in reading, writing, and counting. Most of the parents also often do not recognize the type of disorder in their child that should be known by the symptoms experienced by the child. This expert system was built to diagnose types of learning disorders in children aged 5-10 years. From this expert system can provide information about the types of disorders and their prevention. This expert system uses the Forward Chaining and Certainty Factor inference methods. Consultation test results with this system indicate that the system is able to determine the type of disturbance along with the initial solution that must be done, based on the symptoms previously selected by the user.
\end{abstract}

Keywords: Expert System, Forward Chaining, Certainty Factors, Learning Disorders

\section{PENDAHULUAN}

Sistem pakar adalah sebuah program komputer yang menggunakan pengetahuan manusia untuk memecahkan masalah yang biasanya akan memerlukan kecerdasan manusia. Sistem pakar merupakan pengetahuan keahlian tentang masalah tertentu, sebagai data atau aturan yang dapat dipanggil bila diperlukan. Sistem pakar juga dapat memberikan beberapa analisis masalah bahkan dapat merekomendasikan tindakan pengguna untuk melakukan perbaikan dan pembetulan.

Sistem pakar dikembangkan dalam berbagai bidang, termasuk dalam bidang medis, kesehatan, dan ilmu pengetahuan lainnya. Pada penelitian ini penulis ingin membahas tentang penerapan sistem pakar untuk mendeteksi dini gangguan belajar pada anak.

Gangguan belajar pada anak penting untuk dideteksi sejak dini. Hal ini karena gangguan belajar dapat mempengaruhi perasaan dan perilaku anak. Lebih jauh lagi, gangguan belajar pada anak bisa berakibat pada rasa frustrasi, marah oleh karena kegagalan dalam prestasi akademik yang akhirnya menyebabkan munculnya gangguan depresi yang kronis. Oleh karenanya penting sekali untuk ditangani secara serius dan untuk menangani masalah tersebut, dibutuhkan suatu sistem yang bisa mendeteksi gangguan belajar pada anak serta memberikan solusi mengenai permasalahan tersebut. 


\section{METODE PENELITIAN}

Adapun data yang dihasilkan dalam sistem yang didapat dari wawancara dan buku yang berhubungan dengan gangguan belajar pada anak. Data-data gejala yang digunakan dalam sistem pakar deteksi gangguan belajar pada anak ini ada 33 gejala dan dapat dilihat pada tabel 1 berikut:

\section{Tabel 1. Data Learning Disabilities}

\begin{tabular}{|c|l|}
\hline Kode & \multicolumn{1}{|c|}{ Nama Learning disabilities } \\
\hline P01 & Gangguan menulis (Disgrafia) \\
\hline P02 & Gangguan membaca (Disleksia) \\
\hline P03 & Gangguan matematika (Diskalkulia) \\
\hline
\end{tabular}

Tabel 2. Gejala Gangguan Belajar

\begin{tabular}{|c|c|}
\hline Kode Gejala & Gejala \\
\hline R01 & Sulit memegan pensili bolpoin. \\
\hline R02 & Cara memegang alat tulis seringkali terlalu dekat dan hamper menempel pada kertas. \\
\hline $\mathrm{RO3}$ & Cara menulis tidak konsisten dan tidak mengikuti alur garis. \\
\hline R04 & Ukuran dan bentuk huruf tidak proposional. \\
\hline R05 & Berbicara sendiri / terlalu memperhatikan tangan ketika menulis. \\
\hline R06 & Tidakk konsisten dalam penggunaan hurof \\
\hline R07 & besar dan hurof kecil ketika menvilis. \\
\hline R08 & Tampak bervasha keras dalam menyampaikan ide lewrat tulisan. \\
\hline R09 & Sulit menyalin tulisan meskipun svdah ada contoh. \\
\hline R10 & Sulit melakukan proses matematika $(\mathrm{X} /,+-)$. \\
\hline R11 & Sering melakukan kesalahan ketika melakukan perhitungan angka-zngka (ex: deret hittung, deret \\
\hline R12 & Bingung saat ditanya sekarang jam berapa. \\
\hline R13 & Tidalk dapat membaca dan memahami peta atau petunjuk arah yang lain. \\
\hline R14 & Bingung dalam mengurut kejadian waktu (ex: besok, kemarin, lvasa). \\
\hline$R 15$ & Kemampuan bahasa dan kemampuan lainnya tidak mengalami gangguan. \\
\hline$R 16$ & Solit mempelajuri notasi music dan tangga nada. \\
\hline R17 & Sulit menghitung socre dalam aktifitas olahraga. \\
\hline R18 & Sulit melakukan perhitungan matematis (ex: menghitung kembalian uang). \\
\hline R19 & Sulit mengenal huruf. \\
\hline$R 20$ & Kesvlitan mengeja. \\
\hline R21 & Huruf sering tertukar (ex: $d b, p / q, m / w)$ \\
\hline R22 & Kesvlitan dalam mengingat kata-kata. \\
\hline 223 & Kata-kata sering tertukar (ex: dia-ada, sama-masa). \\
\hline R24 & Menghilangkan kata penghuboung (di, ke, pada). \\
\hline$R 25$ & Mengabaikan kata awalan pada saazt membaca (ex: menulis-tulis) \\
\hline$R 26$ & Kesvlitan memahami kalimat yang dibaca atav didengar. \\
\hline R27 & Daya ingat jangka pendek buruk. \\
\hline R28 & Tidakk dapat membaca dan membunyikan kata yang barv dilihat dan didengar. \\
\hline 229 & Kesvlitan membuat pekerjaan tertulis secara terstruktur (ex:essai). \\
\hline R30 & Rentang perhatian pendekk ketika mendengarkan sesvatv. \\
\hline R31 & Tulisan tangan jelek. \\
\hline R32 & Sulit mempelajari tulisan sambong \\
\hline R33 & lambat dar \\
\hline
\end{tabular}

Dari pengetahuan berupa gejala dan gangguan belajar pada anak, maka dapat dibuat basis pengetahuan berupa hubungan atau keterkaitan yang ada antara gejala dan gangguan belajar pada anak.

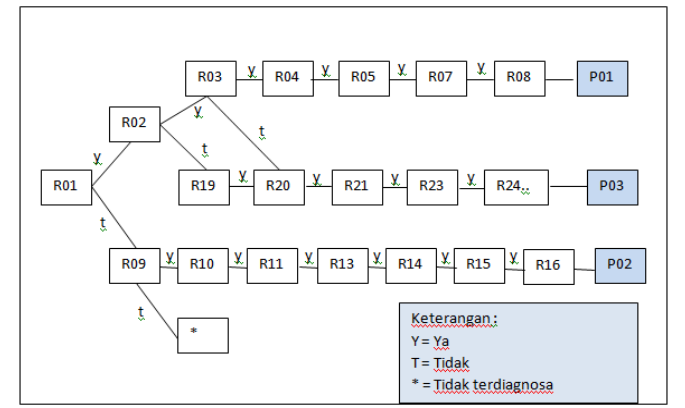

Tabel Rule

Gambar 1. Pohon Keputusan

Dari data yang sudah didapatkan maka didapat rule dari sistem pakar deteksi dini gangguan belajar pada anak sebagai berikut:

Tabel 3. Rule

\begin{tabular}{|c|c|}
\hline 16 & Bit: \\
\hline \multirow[t]{5}{*}{1.} & 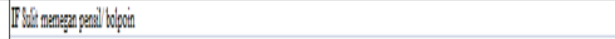 \\
\hline & 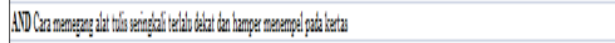 \\
\hline & 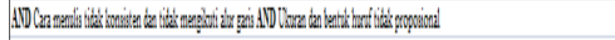 \\
\hline & 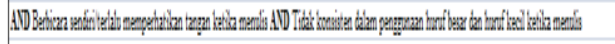 \\
\hline & 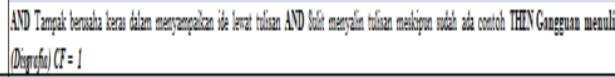 \\
\hline \multirow[t]{9}{*}{1} & 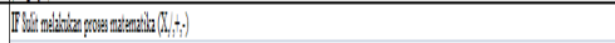 \\
\hline & 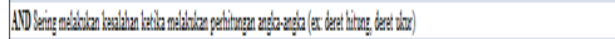 \\
\hline & 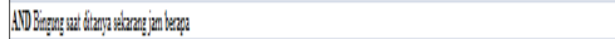 \\
\hline & 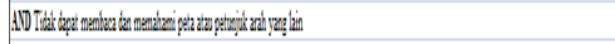 \\
\hline & 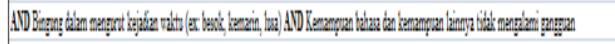 \\
\hline & 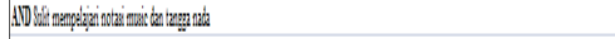 \\
\hline & 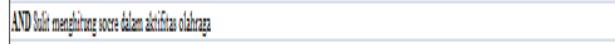 \\
\hline & 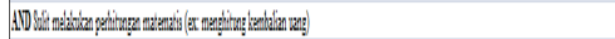 \\
\hline & 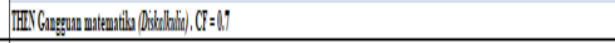 \\
\hline \multirow[t]{13}{*}{. } & 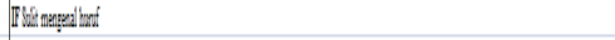 \\
\hline & ADVexitamang \\
\hline & ADExivingetize (edoppar) \\
\hline & 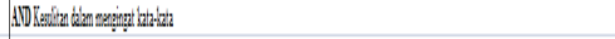 \\
\hline & 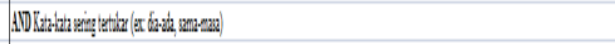 \\
\hline & 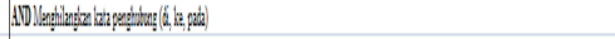 \\
\hline & 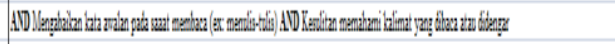 \\
\hline & 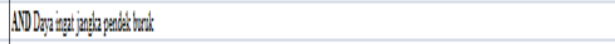 \\
\hline & 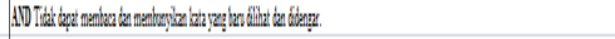 \\
\hline & 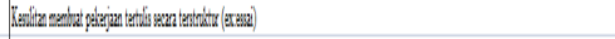 \\
\hline & 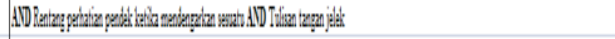 \\
\hline & 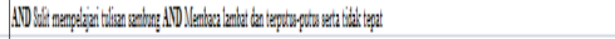 \\
\hline & 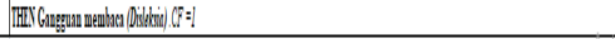 \\
\hline
\end{tabular}

Besaran nilai $\mathrm{CF}$ yang digunakan dalam penelitian ini berkisar antara 0 sampai dengan 1. Nilai 0 menunjukkan ketidakpastian mutlak, sedangkan nilai 1 menujukkan kepercayaan mutlak. Rentang nilai ini dibagi menjadi 3 kategori berdasarkan atas tingkat tinggi rendahnya gangguan belajar.

1. Gejala gangguan ringan dengan rentang nilai CF antara $0.1-0.3$

2. Gejala gangguan sedang dengan rentang nilai $\mathrm{CF}$ antara $0.31-0.7$ 
3. Gejala gangguan berat dengan rentang nilai $\mathrm{CF}$ antara $0.71-1$

User memasukkan nilai kepercayaan atau nilai ketidakpastian berdasarkan atas tingkat gangguan. Nilai $\mathrm{CF}$ yang digunakan dalam penelitian ini merujuk pada teori kepastian oleh Shortliffe Buchaman dalam pembuatan MYCIN ( Wesley, 1984). $\mathrm{CF}(\mathrm{H}, \mathrm{E})=$ $\mathrm{MB}(\mathrm{H}, \mathrm{E})$ - $\mathrm{MD}(\mathrm{H}, \mathrm{E})$. Berdasarkan teori tersebut maka dapat dijabarkan sebagai berikut :

$\mathrm{MB}(\mathrm{H}, \mathrm{E})=$ Ukuran kenaikan kepercayaan (measure of increased belief) terhadap hipotesis $\mathrm{H}$ yang dipengaruhi oleh gejala $\mathrm{E}$, Besaran nilai kepercayaan ini sangat tergantung dari besaran nilai kepercayaan yang diberikan oleh user. $\mathrm{CF}$ user diperoleh dengan mengunakan rumus : Max[masukan CF user berdasarkan gejala pilihan]

1. Gangguan menulis (Disgrafia)

$$
\begin{aligned}
& =\max [0.5,0.7,0.8,0.7,0.6] \\
& =0,8
\end{aligned}
$$

2. Gangguan matematika (Diskalkulia)

$$
=\max [0.3,0.7,0.6,0.9,0.8]
$$$$
=0.9
$$

3. Gangguan membaca (Disleksia). $=\max [0.6,0.3,0.6,0.2,0.5]$ $=0.6$

$\mathrm{MD}(\mathrm{H}, \mathrm{E}) \quad=\quad$ Ukuran kenaikan ketidakpercayaan ( measure of increased disbelief) terhadap hipotesis $\mathrm{H}$ yang dipengaruhi oleh gejala $\mathrm{E}$.

Besaran nilai ketidakpercayaan didapat berdasarkan masukan besaran nilai $\mathrm{CF}$ dari User. CF user diperoleh dengan mengunakan rumus : Min[masukan $\mathrm{CF}$ user berdasarkan gejala pilihan]

1. Gangguan menulis (Disgrafia)

$$
\begin{aligned}
& =\min [0.5,0.7,0.8,0.7,0.6] \\
& =0,5
\end{aligned}
$$

2. Gangguan matematika (Diskalkulia) $=\min [0.3,0.7,0.6,0.9,0.8]$ $=0.3$

3. Gangguan membaca (Disleksia). $=\min [0.6,0.3,0.6,0.2,0.5]$ $=0.2$

Berdasarkan teori tersebut diatas maka akan didapat nilai CF ( Certainty Factor ) sebagai berikut :

$$
\mathrm{CF}(\mathrm{H}, \mathrm{E})=\mathrm{MB}(\mathrm{H}, \mathrm{E})-\mathrm{MD}(\mathrm{H}, \mathrm{E}) .
$$

1. Gangguan menulis (Disgrafia)

$$
=0.8-0,5=0.3
$$

2. Gangguan matematika (Diskalkulia)

$$
=0.9-0.3=0,6
$$

3. Gangguan membaca (Disleksia).

$$
=0.6-0.2=0.4
$$

Dari perhitungan diatas, terlihat bahwa nilai $\mathrm{CF}(\mathrm{H}, \mathrm{E})$ berbeda-beda, dan dapat disimpulkan bahwa semakin besar nilai $C F$ peluang terbesar user tersebut mengalami gangguan belajar begitu juga sebaliknya semakin kecil nilai $C F$ maka semakin kecil user tersebut mengalami gangguan belajar.

\section{HASIL DAN PEMBAHASAN}

\section{A. Tampilan halaman depan}

Berikut adalah tampilan program sistem pakar deteksi dini gangguan belajar anak dengan metode forward chaining:

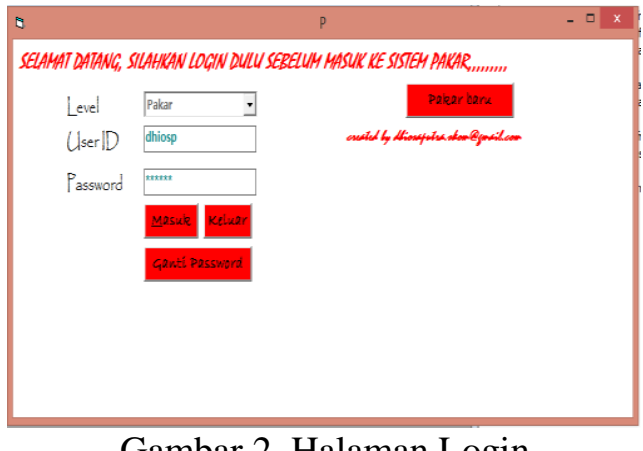

\section{B. Tampilan Menu Utama}

Berikut adalah tampilan menu utama dari sistem pakar deteksi dini gangguan belajar pada anak.

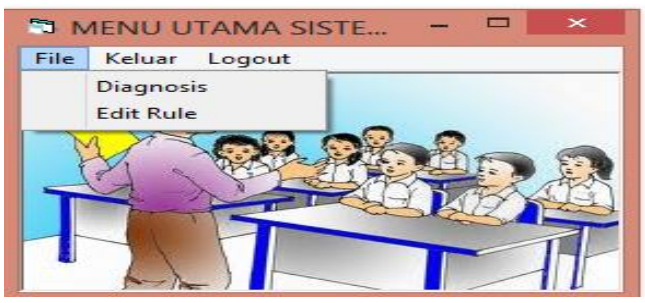

Gambar 3. Menu Utama

\section{Tampilan Diagnosa}

Berikut ini adalah gambar tampilan diagnosa dari sistem pakar 


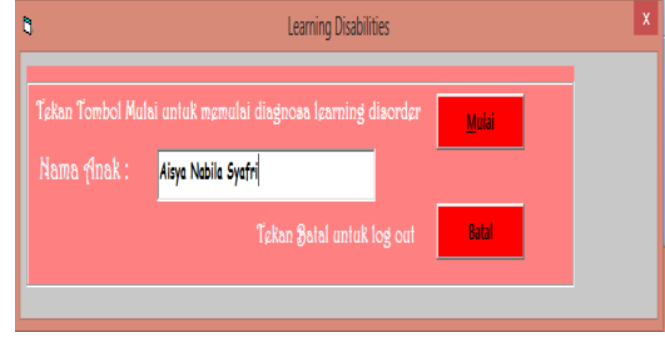

Gambar 4. Tampilan Diagnosa

\section{Tampilan Pertanyaan}

Tampilan pertanyaan dari sistem pakar dapat dilihat pada gambar di bawah ini:

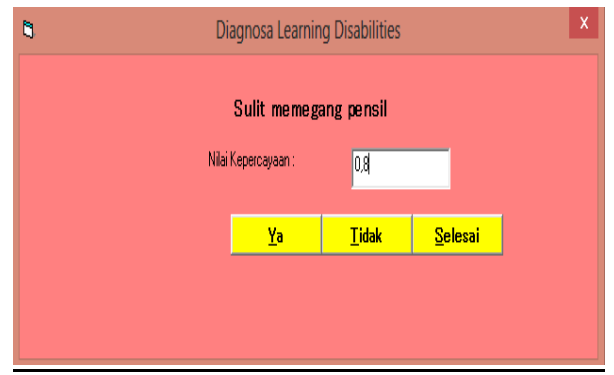

Gambar 5. Tampilan Pertanyaan

\section{E. Tampilan Hasil Diagnosa}

Tampilan hasil diagnosa dapat dilihat pada gambar dibawah ini:

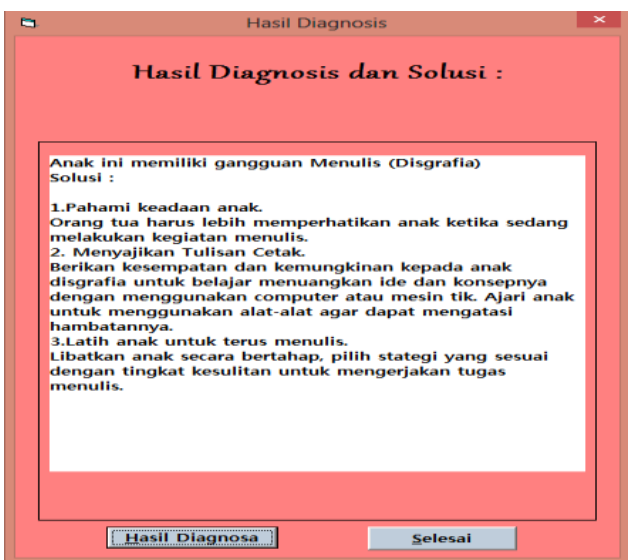

Gambar 6. Tampilan Hasil Diagnosa

\section{F. Tampilan Basis Pengetahuan}

Berikut ini adalah gambaran dari basis pengetahuan sistem pakar deteksi dini gangguan belajar anak

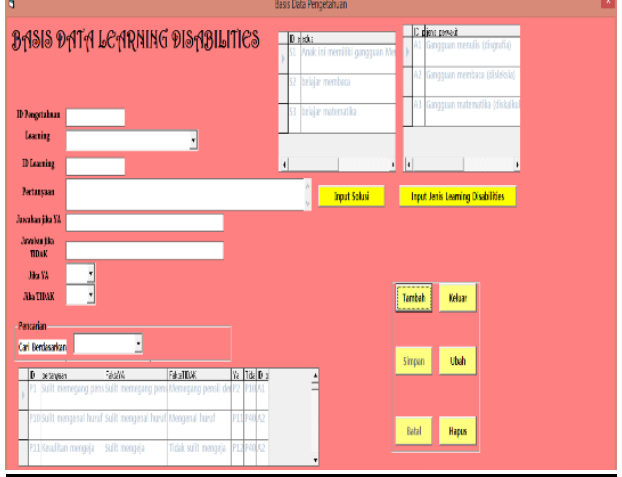

Gambar 7. Tampilan Basis Pengetahuan

\section{G. Tampilan Edit Solusi}

Gambar di bawah ini merupakan tampilan edit solusi dari sistem

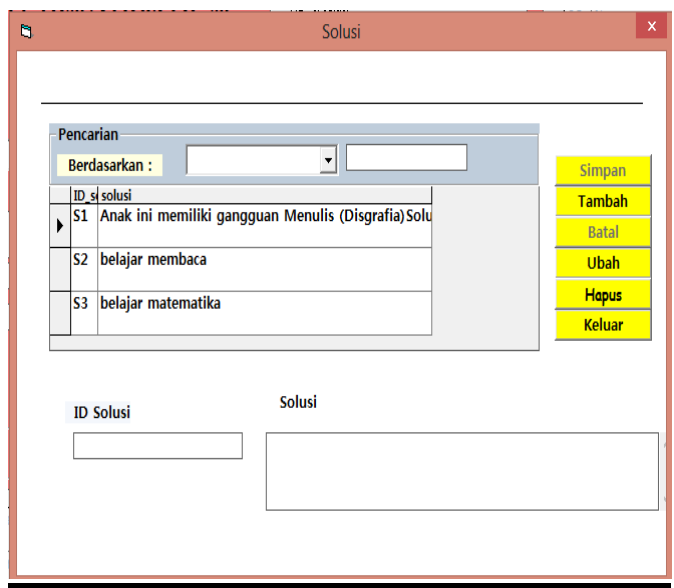

Gambar 8. Edit Solusi

\section{H. Tampilan Edit Learning Disabilities}

Dibawah ini adalah gambar edit learning disabilities

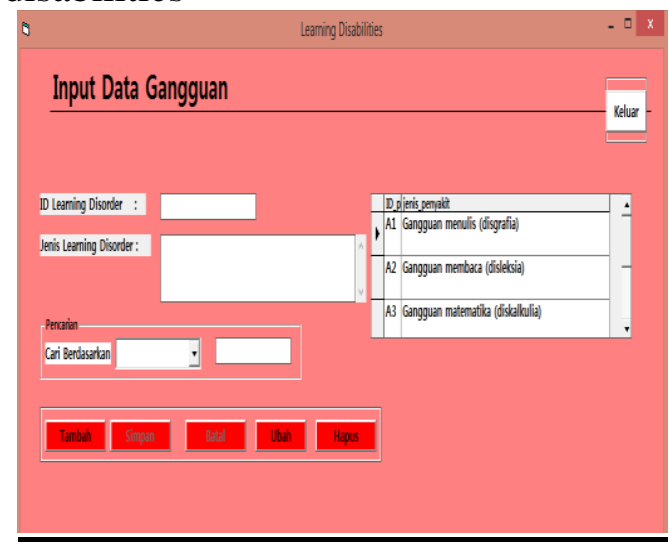

Gambar 9. Tampilan Edit Learning 


\section{DAFTAR PUSTAKA}

Kusumadewi, Sri. 2003. Artificial Intelligence. Graha Ilmu : Yogyakarta.

Ormrod, Jeanne Ellis.2009.Psikologi Pendidikan.Erlangga : Jakarta

Santrock, John W.2009.Psikologi PendidikanEducationalPsychology.S alemba Humanika : Jakarta

Slavin, $\quad$ Robert.2011.Psikologi Pendidikan Teori dan Praktek. Indeks : Jakarta

Hartati, Sri \& Iswanti, Sari. 2008. Sistem Pakar \& Pengembangannya. Graha ilmu : Yogyakarta.

Kusrini. 2006. Aplikasi Sistem Pakar. Penerbit ANDI : Yogyakarta.

Sarma, Shikhar Kr.2010. An Expert System for diagnosis of diseases in Rice Plant

Patra, P.Santosh Kumar.2010. An Expert System for Diagnosis of Human Diseases

Hussain, Wan.2010. Artificial Intelligence In Medical Application: An Exploration

Bilgi ,Mr. N .B.2012. An Expert System using A Decision Logic Charting Approach for Indian Legal Domain With specific reference to Transfer of Property Act

Castaño, Bonifacio.2008. Artificial Intelligence and Bluetooth Techniques in a Multiuser M-learning Domain
Santoso, Leo Willyanto.2010. Perancangan dan Pembuatan Aplikasi Sistem Pakar Untuk Penentuan Produk dan Jenis Perawatan Tubuh di Pusat Perawatan "Epiderma" 